\title{
An In Vitro Microbiological Study Evaluating the Efficacy of Soluneem (A Water Soluble Neem Formulation from Azadirachta Indica) Against Periodontopathic Microorganisms
}

\author{
Shefali Sharma', Suchetha $A^{2}$, Vijayendra $R^{3}$, Bharwani Ashit $G^{4}$
}

\section{ABSTRACT}

Objectives: To evaluate the efficacy of Soluneem (a water soluble formulation from the neem seed kernel from Azadirachta Indica containing Azadirachtin) as an antimicrobial agent and the effective concentration of Soluneem required to inhibit periodontopathic bacteria and to compare it with a known antiplaque agent chlorhexidine $(0.2 \%)$ in vitro.

Material and Methods: The subgingival plaque samples from a total of 20 sites from 5 patients (4 sites per patient) was taken with a probing pocket depth of $\geq$ " $5 \mathrm{~mm}$. Subgingival plaque samples were collected, cultivated, and incubated anaerobically as per the standard procedure. Further subculturing was done to obtain pure growth. Various biochemical tests were used for identifying each organism as per the standard protocol. The sensitivity to the varying concentrations of neem like $100 \%, 50 \%, 25 \%, 12.5 \%, 6.25 \%, 3.125 \%$ and $1.5625 \%$ and $0.2 \%$ Chlorhexidine solution was tested using the Modified Disc diffusion method. The sensitivity was tested by measuring the zones of inhibition comparing with the known standard diameter.

Results: The organisms isolated and percentage of identification rate from total of five patients was $60 \%$ for Bacteroids fragilis, 40\% for Bacteroids distasonis, 20\% for Prevotella corporis, 20\% for Prevotella melaninogenica, and 20\% for Peptostreptococus species. Chlorhexidine $0.2 \%$ was effective against micro organisms cultivated and isolated in this study. However Soluneem was not effective against the organisms cultivated in this study.

Conclusion: Soluneem had no effect on the growth of any of the isolated organisms. Further studies testing soluneem against other putative periodontal pathogens with Azadirachtin are warranted.

Keywords: Azadirachtin, Microbial sensitivity testing, Soluneem, Zone of inhibition.

${ }^{1}$ M.D.S Senior Lecturer

Dept. of Periodontia

Seema Dental College and Hospital,

Rishikesh, India

\section{Contact Autbor}

Dr. Bharwani Ashit G dr.bharwani@yahoo.in

J Oral Health Comm Dent 2012;6(1)4-9
${ }^{2}$ M.D.S, Professor and Head

Dept. of Periodontics

D.A. Pandu Memorial R.V. Dental College, Bangalore, India

${ }^{3}$ M.D.S, Former Head of Department, Dept of Periodontics

D.A. Pandu Memorial R.V. Dental College, Bangalore, India

${ }^{4}$ Post Graduate student, Dept. of Periodontics D.A. Pandu Memorial R.V. Dental College, Bangalore, India

\section{INTRODUCTION}

he development of chemothera peutic agents capable of inhibiting dental plaque formation has been of great interest to dental researchers and clinical dentists over the past decade (1). In the recent years, human pathogenic microorganisms have developed resistance in response to the indiscriminate and long term use of antimicrobial drugs commonly 
employed in the treatment of infectious diseases. The undesirable side effect of certain antibiotics, and the emergence of previously uncommon infections, has made the scientists to look for new antimicrobial substances of alternate sources like plant origin. Therefore plants represent a potential source of new anti-infective agents (2).

Indians have used herbal products for oral care for centuries. Most common ones being extracts of Mango (Mangifera indica), Neem (Azadirachta indica; Melia azadirachta), and Tea-dust (Camellia sinensis) (3).The most widely used herbal product among them is Neem and its products. The Neem twig has been used from time immemorial for cleansing the teeth and the juice extracted by it's chewing was believed to be beneficial for toning the gums (4). The widespread use of the Neem "chewing stick" as an oral hygiene device in certain Asian and African countries has suggested that it may possess some anti-plaque properties also. Dentists in areas where it is in use, have noted its effectiveness in preventing certain plaquerelated dental diseases (1).

Several studies have reported the antibacterial effects of chewing sticks on periodontotal pathogens particularly Bacteriodes species and inhibitory action on dental plaque formation $(1,4,5,6)$.

The quest for identifying the various chemotherapeutic agents in neem has led to the isolation of more than $135 \mathrm{com}$ pounds. The compounds have been divided into two major classes: isoprenoids and others. The isoprenoids includes azadirachtin (7).

Azadirachtin has been found to inhibit enzymatic activity of larvae of Drosophila melanogaster, adult female Aedes aegypti, the larvae of Manduca sexta(8) and blackheaded caterpillar (9). The Neem seed kernel extracts and oil containing azadirachtin has shown antibacterial activity and activity against dermatophytes $(10,11)$. One such example of a compound containing azadirachtin is Soluneem ${ }^{\mathrm{TM}}$. Soluneem is a water soluble formulation from the neem seed kernel from Azadirachta Indica containing Azadirachtin -A 6\%.
Earlier preparations from the Neem seed kernel were available as emulsified concentrates and required many solvents. These degrade very quickly in the presence of water or sunlight. Soluneem is highly stable even at $110^{\circ} \mathrm{C}$, whereas technically Neem Seed Kernel Extracts (NSKE) is thermolabile. The unique advantage of this preparation is that it is a water soluble formulation which will have, a potentiated action and it contains the compound azadirachtin (9).

The insecticidal activity of this product has been confirmed and it has been suggested that it may have other applications in the field of personal care. In the present study an attempt has been made to explore the effective concentration of Soluneem required to inhibit periodontopathic microorganisms and to compare Soluneem with antibacterial efficacy of chlorhexidine which is considered as the gold standard in periodontics (12).

\section{MATERIALS AND METHODS}

Patients diagnosed with chronic periodontitis and attending the Department of Periodontics, D.A.P.M.R.V. Dental College, Bangalore, formed the study group.

Patients were explained about the purpose of the investigation and a written consent was taken prior to commencement of the study. Ethical clearance was obtained by the ethical committee of the institution.

Commercially available Chlorhexidine with a concentration of $0.2 \%(\mathrm{w} / \mathrm{v})$ was selected for the study to be compared for its efficacy with Soluneem.

\section{INCLUSION CRITERIA}

Patient aged $30-55$ years with a diagnosis of chronic periodontitis; free from systemic disease and who had not undergone any form of non surgical/surgical periodontal therapy in the last 6 months were included in the study.

\section{EXCLUSION CRITERIA}

Patient with a known systemic disorder, pregnant women, smokers, and patients who received any topical or systemic anti- biotic treatment for any purpose in the past 6 months including the use of mouthwash were excluded from the study.

\section{STUDY DESIGN}

The study was carried out using 20 subgingival plaque samples from patients diagnosed with chronic periodontitis. The subgingival plaque samples from periodontal pockets $\geq$ " $5 \mathrm{~mm}$ were collected. Supragingival plaque was removed with hand instruments and the subgingival plaque was collected by inserting a sterilized Gracey curette (Area-specific curette) into the deepest portion of the periodontal pocket (13).

The plaque samples collected were plated immediately onto 5\% sheep blood agar, Brucella Blood Agar (BBA) and Kanamycin Vancomycin Laked Blood Agar (KVLBA) using sterile nichrome wire loop (14).This was immediately transferred into an anaerobic jar with gas pack system (Figure-1). The sheep blood agar plates were incubated aerobically at $37^{\circ} \mathrm{C}$ for $72 \mathrm{hrs}$; BBA and KVLBA were incubated anaerobically at $37^{\circ} \mathrm{C}$ for 72 hours.

The gram stain smear from each patient was examined for the presence of bacteria and pus cells (15) (Figure-2). Individual colony morphotypes were subcultured onto Chocolate Agar (aerobic inoculation for aerotolerance) and Brucella Blood Agar enriched with Vitamin-K and Heame for obtaining pure growth. These were fur-

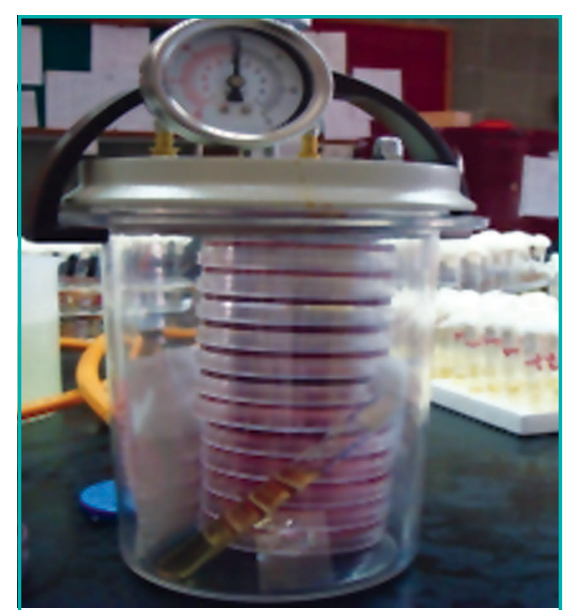

Figure 1: Anaerobic jar with gas pack system 


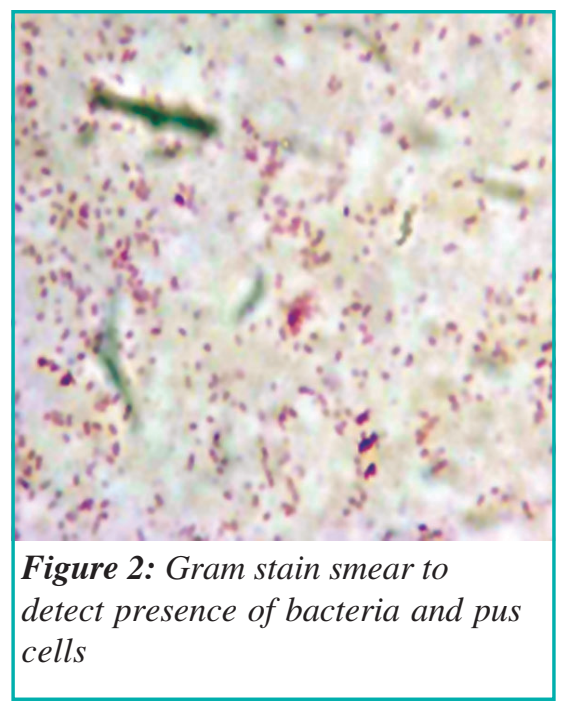

ther identified using standard biochemical tests which included: Indole production, Nitrate reduction, Aesculin hydrolysis, Growth in Bile, Fermentation Tests-Glucose, Sucrose, Malt, lactose, Rhamnose, galactose, Arabinose, Salicin, mannitol, and trehalose. Aerobic bacteria were also identified as a part of the project using standard methods $(16,17)$.

For sensitivity testing 3-4 identical colonies were inoculated into anaerobic basal broth incubated for 4-6 hrs at $37^{\circ} \mathrm{C}$. Brucella blood agar plates were inoculated using a sterile cotton swab.

The sensitivity to $0.2 \%$ Chlorhexidine and varying concentrations of neem like $100 \%$, $50 \%, 25 \%, 12.5 \%, 6.25 \%, 3.125 \%$ and $1.5625 \%$ was tested. The plates were incubated at $37^{\circ} \mathrm{C}$ for $48 \mathrm{hrs}$ anaerobically and the zones of inhibition were recorded and interpreted comparing with the standard. Modified Disc diffusion method on Brucella Blood Agar plates was used.

Preparation of dilutions of Soluneem powder

The dilutions of the Soluneem powder was made by first preparing a saturated solution of the powder in distilled water, that is taken as $100 \%$, and further dilutions were made from the standard saturated solution of $100 \%$.

The organisms were found sensitive to Chlorhexidine $0.2 \%$ if the diameter of zone of inhibition was $\geq " 6.1 \mathrm{~mm}$ (18).The standard strain ATCC Bacteroides fragilis was included for biochemical reactions and sensitivity testing (14).

\section{RESULTS}

Dental plaque inoculated from the samples gave a confluent growth with varied

\begin{tabular}{|c|c|c|c|c|c|}
\hline \multicolumn{6}{|c|}{$\begin{array}{l}\text { TABLE 1: BIOCHEMICAL TESTS } \\
\text { Table 1.1: Biochemical tests of Prevotella corporis } \\
\qquad(+) \rightarrow \text { Positive and }(-) \rightarrow \text { Negative }\end{array}$} \\
\hline \multicolumn{6}{|c|}{ Prevotella Corporis } \\
\hline Indole & Nit & Bile Broth & Glucose & Sucrose & Malt \\
\hline$\tilde{\boldsymbol{n}}$ & $\tilde{\boldsymbol{n}}$ & Resistant & + & + & + \\
\hline Lactose & Arabinose & Rhamnose & Trehalose & Salicin & Esculin \\
\hline$\tilde{n}$ & $\tilde{\boldsymbol{n}}$ & $\tilde{n}$ & $\tilde{n}$ & $\tilde{\boldsymbol{n}}$ & $\tilde{\boldsymbol{n}}$ \\
\hline
\end{tabular}

Table 1.2: Biochemical tests of Prevotella melaninogenicas
$(+) \rightarrow$ Positive and $(-) \rightarrow$ Negative
\begin{tabular}{|lccccc|} 
Prevotella & Melaninogenica \\
\hline Indole & Nitrate & Bile Broth & Glucose & Sucrose & Malt \\
\hline$\tilde{\boldsymbol{n}}$ & $\tilde{\boldsymbol{n}}$ & Resistant & + & + & + \\
Lactose & Arabinose & Rhamnose & Trehalose & Salicin & Esculin \\
- & - & - & + & - & - \\
\hline
\end{tabular}

Table 1.3: Biochemical tests of Bacteroides distasonis $(+) \rightarrow$ Positive and $(-) \rightarrow$ Negative

\begin{tabular}{|lccccc|}
\hline Bacteroides & Distasonis & & & \\
\hline Indole & Nitrate & Bile Broth & Glucose & Sucrose & Malt \\
\hline$\tilde{\boldsymbol{n}}$ & $\tilde{\boldsymbol{n}}$ & Sensitive & + & + & + \\
Lactose & Arabinose & Rhamnose & Trehalose & Salicin & Esculin \\
+ & $\tilde{\boldsymbol{n}}$ & $\tilde{\boldsymbol{n}}$ & + & + & + \\
\hline
\end{tabular}

Table 1.4: Biochemical tests of Bacteroides fragilis $(+) \rightarrow$ Positive and $(-) \rightarrow$ Negative

\begin{tabular}{|lccccc|}
\hline Bacteroides & Fragilis & & & \\
\hline Indole & Nitrate & Bile Broth & Glucose & Sucrose & Malt \\
\hline- & - & Sensitive & + & + & + \\
Lactose & Arabinose & Rhamnose & Trehalose & Salicin & Esculin \\
+ & $\tilde{\boldsymbol{n}}$ & $\tilde{\boldsymbol{n}}$ & $\tilde{\boldsymbol{n}}$ & $\tilde{\boldsymbol{n}}$ & $\tilde{\boldsymbol{n}}$ \\
\hline
\end{tabular}

Table 1.5: Biochemical tests of Peptostreptococcus $(+) \rightarrow$ Positive and $(-) \rightarrow$ Negative

\begin{tabular}{|lccccc|}
\hline \multicolumn{7}{l}{ Peptostreptococcus Species } \\
\hline Indole & Nitrate & Bile Broth & Glucose & Sucrose & Malt \\
\hline- & - & Resistant & + & + & + \\
Lactose & Arabinose & Rhamnose & Trehalose & Salicin & Esculin \\
$\tilde{n}$ & $\tilde{n}$ & $\tilde{n}$ & $\tilde{n}$ & $\tilde{n}$ & $\tilde{n}$ \\
\hline
\end{tabular}




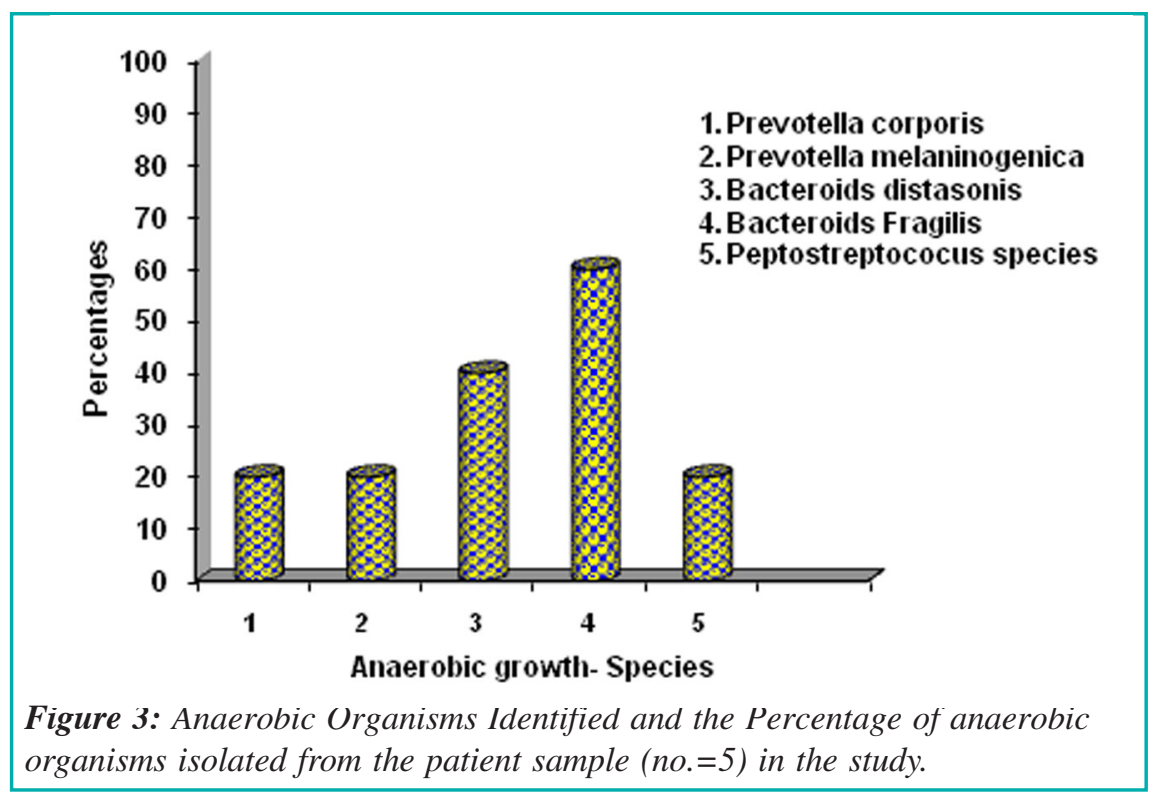

total of five patients was- $20 \%$ for Prevotella corporis, 20\% for Prevotella melaninogenica, $60 \%$ for Bacteroids distasonis, $60 \%$ for Bacteroids fragilis, and $20 \%$ for Peptostreptococus species.

Table 1 shows the results of the biochemical tests used for identification. Graph 1 shows the anaerobic isolates obtained.

- Microbial sensitivity testing: The microbial sensitivity testing showed:

- Bacteroides fragilis and distasonis was found to be sensitive to chlorhexidine, but resistant to neem concentrations of $100 \%, 50 \%, 25 \%$, $12.5 \%, 6.25 \%, 3.125 \%$, and $1.5625 \%$
- Prevotella melaninogenica and corporis was sensitive to chlorhexidine. Prevotella species were resistant to $100 \%, 50 \%, 25 \%, 12.5 \%, 6.25 \%$, $3.125 \%$, and $1.5625 \%$ neem concentrations.

- Peptostreptococci was sensitive to chlorhexidine, resistant to neem concentrations.

- ATCC Bacteroides fragilis was found to be sensitive to chlorhexidine, but resistant to $100 \%, 50 \%, 25 \%, 12.5 \%$, $6.25 \%, 3.125 \%$, and $1.5625 \%$ neem concentration.

Table 2 gives the microbial sensitivity pat- tern with the antibiotics, chlorhexidine and Soluneem.

\section{DISCUSSION}

The local application of antimicrobial agents suppresses periodontal pathogens and increases the clinical and microbial benefits of mechanical debridement. Topical treatment with $0.2 \%$ chlorhexidine gluconate has been found to be particularly effective for the control of supragingival plaque to cause positive clinical and microbiologic periodontal changes (19). The undesirable side effect of certain antibiotics, and the emergence of previously uncommon infections, has forced scientists to look for new antimicrobial substances from various sources, such as medicinal plants (4).In this study, subgingival plaque from a total of 20 sites from 5 patients ( 4 sites per patient) was taken. Four sites from each patient was taken, since it has been shown that four individual subgingival specimens, each from the deepest periodontal pocket in each quadrant, should be pooled to be able to detect highest amount of periodontal pathogens (20). The same number of sites were also taken in a study by Wennstrom et al (21).

The predominant isolate in this study was of Bacteroides species - Bacteroids fragilis. This was in accordance with study by Drink and Tanner et al,. wherein Bacteroides spe-

\section{Table 2: Microbial sensitivity pattern with Soluneem and chlorhexidine}

\begin{tabular}{|c|c|c|c|c|c|c|c|c|}
\hline & Neem $100 \%$ & $50 \%$ & $25 \%$ & $12.50 \%$ & $6.25 \%$ & $3.13 \%$ & $1.56 \%$ & Chlorhexidine \\
\hline \multicolumn{9}{|l|}{$P t 1$} \\
\hline Prevotella meloninogenica & $\mathrm{R}$ & $\mathrm{R}$ & $\mathrm{R}$ & $\mathrm{R}$ & $\mathrm{R}$ & $\mathrm{R}$ & $\mathrm{R}$ & $\mathrm{S}$ \\
\hline Bacteroides distasonis & $\mathrm{R}$ & $\mathrm{R}$ & $\mathrm{R}$ & $\mathrm{R}$ & $\mathrm{R}$ & $\mathrm{R}$ & $\mathrm{R}$ & S \\
\hline \multicolumn{9}{|l|}{ Pt2 } \\
\hline Bacteroides fragilis & $\mathrm{R}$ & $\mathrm{R}$ & $\mathrm{R}$ & $\mathrm{R}$ & $\mathrm{R}$ & $\mathrm{R}$ & $\mathrm{R}$ & S \\
\hline Bacteroides distasonis & $\mathrm{R}$ & $\mathrm{R}$ & $\mathrm{R}$ & $\mathrm{R}$ & $\mathrm{R}$ & $\mathrm{R}$ & $\mathrm{R}$ & $S$ \\
\hline \multicolumn{9}{|l|}{ Pt3 } \\
\hline Pepto streptococci species & $\mathrm{R}$ & $\mathrm{R}$ & $\mathrm{R}$ & $\mathrm{R}$ & $\mathrm{R}$ & $\mathrm{R}$ & $\mathrm{R}$ & $S$ \\
\hline \multicolumn{9}{|l|}{ Pt4 } \\
\hline Bacteroides fragilis & $\mathrm{R}$ & $\mathrm{R}$ & $\mathrm{R}$ & $\mathrm{R}$ & $\mathrm{R}$ & $\mathrm{R}$ & $\mathrm{R}$ & $\mathrm{S}$ \\
\hline \multicolumn{9}{|l|}{ Pt5 } \\
\hline Prevotella corporis & $\mathrm{R}$ & $\mathrm{R}$ & $\mathrm{R}$ & $\mathrm{R}$ & $\mathrm{R}$ & $\mathrm{R}$ & $\mathrm{R}$ & $\mathrm{S}$ \\
\hline Bacteroides fragilis & $\mathrm{R}$ & $\mathrm{R}$ & $\mathrm{R}$ & $\mathrm{R}$ & $\mathrm{R}$ & $\mathrm{R}$ & $\mathrm{R}$ & $S$ \\
\hline $\begin{array}{l}\text { Bacteroides fragilis ATCC } \\
\text { (R-Resistant, S-Sensitive) }\end{array}$ & $\mathrm{R}$ & $\mathrm{R}$ & $\mathrm{R}$ & $\mathrm{R}$ & $\mathrm{R}$ & $\mathrm{R}$ & $\mathrm{R}$ & $S$ \\
\hline
\end{tabular}


cies were detected more often in active than in inactive sites (22). Another study by $A l i$ R. W et al. has found a significant correlation between the presence of these species and pocket depth. Hence plaque from deeper samples will contain larger quantity of Bacteroides species (23).

The finding of the study was in contrast to other studies where $64 \%$ of active sites, $35.7 \%$ of inactive sites and $38.5 \%$ of healthy sites yielded black-pigmented anaerobes (P.gingivalis Prevotella intermedia, Prevotella nigrescens) $(24,25)$. There is also moderate evidence to consider Peptostreptococcus micros as a putative periopathogen (26). This organism was also isolated in $20 \%$ of the samples.

In advanced adult periodontitis, the cultivable flora is comprised mainly of gramnegative anaerobic rods (75\%). P.gingivalis, P.melaninogenicus subspecies intermedius and Fusobacterium nucleatum are the most prominent isolates from advanced lesions (27). Prevotella melaninogenica was also identified in our study.

Another interesting incidental observation is the presence of Prevotella corporis in the samples. Prevotella corporis is normally associated with endodontic flora (28). There are very few reports on its presence in periodontal pocket, one study reported its presence in few samples (29).

The reason for the isolation of the limited species of organisms could have been due to identification criteria differing among laboratories. Even with rigorous testing, identification of some species is questionable. With minimal testing it is even less reliable (30). Another problem could be of keeping periodontopathogenic bacteria viable, which is required for standard cultivation. This may explain the inability to obtain other known periopathogens in sub cultures (31).

The organisms were found to be sensitive to $0.2 \%$ chlorhexidine. This is in agreement with various other studies where chlorhexidine $0.2 \%$ had brought down the microbial counts $(13,28,32)$.
All isolated organisms were found resistant to neem formulation. In another study the authors tested for the antimicrobial effect of the aqueous extract of seven different types of chewing sticks. The study also included the extracts of azadirachta indica (neem). Their result showed no antimicrobial effect of neem even upto $50 \%$ concentration (6). However these studies were based on the extracts of chewing sticks and the present study used the neem seed kernel extract containing Azadirachtin 6\%.

It has been reported in a study that the components from neem leaf and seeds assayed did not show anti-adherence activity of bacteria although the extract from neem bark did exhibit the property against bacterial adherence (1).

Despite the observation that the formulation under study had no antibacterial effect on microorganisms cultivated in this study, the use of neem for oral home care cannot be completely rejected, for the fact remains that neem products in different forms have been effective as antiplaque and antigingivitis agents $(1,4)$.

The various reasons for the Soluneem exhibiting no antimicrobial activity could be that there may be other unidentified components in neem products that are effective and yet to be identified. The DNA of periodontal pathogen may not be susceptible. Other components from neem plant may be effective as antiplaque and antigingivitis agents or have inhibitory actions on microbes as reported in literature. It also could be that more than one ingredients is required for their action against periodontal pathogens (they may have synergistic effects altogether). Also sensitivity tests measure antimicrobial activity against bacteria under laboratory conditions (in vitro activity), not in the patient (in vivo activity) (33).

\section{REFERENCES}

1. Wolinsky LE, Mania S, Nachnani S, et al. The inhibiting effect of aqueous Azadirachta indica (Neem) extract upon bacterial properties influencing in vitro plaque formation. J Dent Res 1996; 75(2): 816-22.
2. Firas A, AL-Bayati, Khudir D. Sulaiman. In vitro antimicrobial activity of Salvadora persica L. extracts against some isolated oral pathogens in Iraq. Turk J Biol 2008;32:57-62.

3. Patel VK, Bhatt HV. Folklore therapeutic indigenous plants in periodontal disorders in India (review, experimental and clinical approach). Int J Clin Pharmacol Ther Toxicol 1988;26(4):176-84.

4. D'Silva I, Magar B. The effect of neem gel on plaque and gingivitis. $J$ Indian Soc Periodontol 1999;2(2).

5. Khalid A. The antimicrobial effects of extracts of Azadirachta indica (Neem) and Salvadora persica (Arak) chewing sticks. Indian J Dent Res 1999;10(1): 23-26.

6. Khalid A. The antimicrobial effects of seven different types of Asian chewing sticks. Odontostomatol Trop 2001;96: 17-20.

7. Biswas K, Chattopadhyay I, Banerjee RK, Bandyopadhyay U. Biological activities and medicinal properties of neem (Azadirachta indica). Current Science 2002;82(11):1336-45.

8. Mitchell MJ, Smith SL, Johnson S, et al. Effects of the neem tree compounds azadirachtin, salannin, nimbin, and 6desacetylnimbin on ecdysone 20monooxygenase activity. Arch Insect Biochem Physiol 1997;35(1-2):199-209.

9. Shivashankar T, Annadurai RS, Srinivas $M$, Preethi G, Sharada TB, Paramashivappa $R$, et al. Control of coconut black-headed caterpillar (Opisina arenosella Walker) by systemic application of 'Soluneem' - A new watersoluble neem insecticide formulation. Current science 2000;78(2):176-78.

10. Natarajan V, Venugopal PV, Menon T. Effect of azadirachta indica (neem) on the growth pattern of dermatophytes. Indian J Med Microbiol 2003;21(2):98101.

11. Das BK, Mukherjee SC, Sahu BB, et al. Neem extract (Azadirachta indica) as an antibacterial agent against fish pathogenic bacteria. Indian J Exp Biol 1999;37(11):1097-1100.

12. Jones CG. Chlorhexidine: is it still the gold standard. Periodontology 2000, 1997; 15:55-62.

13. Jan SM, Sood M, Mehta DS. Effect of scaling and root planning on the composition of the human subgingival microbial flora. J Indian Soc Periodontol 1999;2(3):82-85.

14. Forbes BA, DF Sahm, Weissfeld AS, editors. Bailey and Scott's diagnostic microbiology. $10^{\text {th }}$ ed. St. Louis: Mosby Publication; 1998.

15. Cruikshank R, Duguid JP, Marmion BP, Swain RHA, editors. Medical microbiology. $12^{\text {th }}$ ed. ELBS and Churchill Livingstone; 1974.

16. Collee JG, Fraser AG, Marmion BP, 
Simmons AM, editors. Mackie and McCartney. Practical Medical Microbiology. $14^{\text {th }}$ ed. London: Churchill Livingstone; 1996.

17. Sutter VL, DM Citron, SM Finegold, editors. Wadsworth anaerobic bacteriology manual. $3^{\text {rd }}$ ed. St.Louis: CV Mosby Company; 1980.

18. Schmidlin OA, Zehnder M, Schmidlin PR. Effectiveness of dentine bonding agents against cariogenic bacteria in vitro: a comparison of two methods. Ora Microbiol Immunol 2003;18(3):140-43.

19. Elias Haskel, Judith Esquenasi L. Effects of Subgingival Chlorhexidine Irrigation in Chronic Moderate Periodontitis. J Periodontol 1986;57(5):305-10.

20. Newman MG, Takei HH, Klokkevold PR, Carranza FA, editors: Sanz M, Newman MG Quirynen M. Advanced Diagnostic Techniques: Carranza's Clinical Periodontology. $10^{\text {th }}$ ed. WB Saunders Company; 2007.

21. Wennstrom JL, Heiji L, Dahlen G, et al. Periodic subgingival antimicrobial irrigation of periodontal pockets. I. Clinical observations. J Clin Periodontol 1987;14(9):541-50.
22. Dzink JL, Tanner ACR, Haffajee AD, Socransky SS. Gram negative species associated with active destructive periodontal lesions. J Clin Periodontol 1985; 12(8):648-59.

23. Ali RW, Velcescu C, Jivanescu MC, et al. Prevalence of six putative periodontal pathogens in subgingival plaque samples from Romanian adult periodontitis patients. J Clin Periodontol 1996;23(2): 133-39.

24. Teanpaisan R, Douglas CWI, Walsh TE. Characterisation of black-pigmented anaerobes isolated from diseased and healthy periodontal sites. J Periodontal Res 1995;30(4):245-51.

25. Byakod G, Kothiwale S, Deshpande RN. A Study of plaque $\mathrm{pH}$ with microbial variation with varying depth of gingival crevice in health and disease. J Indian Soc Periodontol 2004;7(2):105-08.

26. Marc Quirynen, Wim Teughels, Marc De Soete, et al. Topical antiseptics and antibiotics in the initial therapy of chronic adult periodontitis: Microbiological aspects. Periodontology 2000 2002;28: 72-90.

27. Genco RJ. Antibiotics in the treatment of human periodontal diseases. $J$ Periodontol 1981;52(9):545-58.

28. Drucker DB, Lilley JD, Tucker D, et al. The endodontic microflora revisited. Microbios 1992;71(288-289):225-34.

29. Salari MH, Kadkhoda Z. Rate of cultivable subgingival period-ontopathogenic bacteria in chronic periodontitis. J Oral Sci 2004;46(3):157-61.

30. Moore WEC. Microbiology of periodontal disease. J Periodontal Res 1987;22: 33541.

31. Jervoe Storm PM, Koltzscher M, Falk $\mathrm{W}$, et al. Comparison of culture and realtime PCR for detection and quantification of five putative periodontopathogenic bacteria in subgingival plaque samples. J Clin Periodontol 2005;32(7):778-83.

32. MacAlpine R, Magnusson I, Kiger R, et al. Antimicrobial irrigation of deep pockets to supplement oral hygiene instruction and root debridement. I Bi-weekly irrigation. J Clin Periodontol 1985;12(7): 568-77.

33. Cheesbrough Monica. District laboratory testing in tropical countries. Cambridge University Press; 2005. 